\title{
Eastern Mediterranean salinification observed in satellite salinity from SMAP mission
}

\author{
Grodsky Semyon A. ${ }^{1,}$, , Reul Nicolas ${ }^{2}$, Bentamy Abderrahim ${ }^{2}$, Vandemark Douglas ${ }^{3}$, \\ Guimbard Sebastien 4 \\ 1 Department of Atmospheric and Oceanic Science, University of Maryland, College Park, USA \\ 2 Institut Francais pour la Recherche et l'Exploitation de la Mer, Plouzane, France \\ 3 University of New Hampshire, Durham, USA \\ * Corresponding author : Semyon A. Grodsky, email address : senya@atmos.umd.edu
}

${ }^{4}$ OceanScope, Plouzané, Brest, France

\begin{abstract}
:
One of the saltiest seas, the Mediterranean, experiences significant salinity variations in near surface layers. Satellite sea surface salinity (SSS) data obtained using Soil Moisture Active Passive (SMAP) mission indicate steady salinification of the eastern Mediterranean Levantine Basin at a rate of $\sim 0.14$ psu/year during 2015-2018. Satellite-observed salinity changes are confirmed by Argo float data and suggest possible changes in properties of the Levantine Intermediate Water. Eastern Mediterranean salinification often coincides with a freshening of the western Ionian Sea. Based on satellite altimetry geostrophic currents, these salinity changes are concurrent with a weakening cyclonic circulation in the Levantine Basin and strengthening anticyclonic circulation in the lonian Sea. The latter is indicative of the Adriatic-Ionian Bimodal Oscillation System. It is known that such circulation changes reduce (increase) the transport of fresh Modified Atlantic Water into the eastern Mediterranean (western Ionian Sea), and this is consistent with observed SSS changes. The quality and availability of satellite L-band $(1.41 \mathrm{GHz})$ SSS estimates near the coast can be limited by land contamination. It is shown that absolute SSS retrievals exhibit up to 1 psu biases in the Mediterranean. This study's use of SMAP SSS anomaly mapping instead of absolute SSS illustrates that observed spatial/temporal SSS patterns allow investigation of time variable change in this basin and augment the existing regional observing system.
\end{abstract}

\section{Highlights}

- Monitoring complexity of Mediterranean processes is an appealing target for remote sensing. Despite strong biases, Mediterranean geophysical signals are contained in satellite SSS fields. During 2015-2018, satellite SSS shows steady salinification of the Levantine at $\sim 0.14$ psu/year. Levantine salinification results from Ionic Sea circulation switch linked with the BIOS pattern. $\rightarrow$ Satellite SSS compliments existing in-situ observation systems due to better spatial resolution. 


\section{List of abbreviations:}

BiOS: Adriatic- Ionian Bimodal Oscillation System

SMAP: Soil Moisture Active Passive

MAW: Modified Atlantic Water

AC: Algerian Current

MMJ: Mid-Mediterranean Jet

LEC: Libyo-Egyptian Current

AMC: Asia Minor Current

LIW: Levantine Intermediate Water 


\section{Introduction}

Significant interest in the Eastern Mediterranean Sea is fueled by a hypothesis that this region may be considered as a fast responding laboratory of processes relevant for the global climate change, which regionally develop on relatively short space and time scales (Malanotte-Rizzoli et al., 2014).

Due to strong net evaporation over the Mediterranean Sea, the relatively fresh Atlantic water is modified to become saltier Mediterranean water before eventually returning to the Atlantic through Gibraltar (e.g., Schroeder et al., 2012). Although the positive evaporation-minusprecipitation, $E-P$, (Fig. 1b) largely explains increased Mediterranean salinity levels in comparison to the neighboring salty Atlantic, the spatial pattern of Mediterranean SSS (Fig. 1a) doesn't resemble the spatial pattern of $E-P$ suggesting significant impacts of currents and river runoff, and their related horizontal salt transport (Fig. 1c).

While a multi-decadal Mediterranean salinification tendency is generally attributable to corresponding changes in the Mediterranean water cycle (strengthening of $E-P$, Mariotti, 2010; Skliris et al., 2018), shorter term salinity variations are also related to changes in wind regime and regional circulation (Demirov and Pinardi, 2002). Salinity variation across the Mediterranean is greatly affected by the transport of fresher Atlantic Water that is modified on its eastward journey due to intense air-sea interactions and becomes a Modified Atlantic Water (MAW, e.g., Font et al., 1998). Along the western Mediterranean, the coastal Algerian Current (AC, Fig. 1c) is its main eastward route (Arnone et al., 1990; Rio et al., 2007). The AC is a geostrophically balanced current confined to the upper $150 \mathrm{~m}$ with average surface velocities of $30-40 \mathrm{~cm} / \mathrm{s}$ and volume transport of $\sim 0.4-0.5 \mathrm{~Sv}$. The AC transport and its associated eddies (e.g., Rio et al., 2007) explain the meridional structure of SSS in the western Mediterranean with fresher water located along the northern coast of Africa (Fig. 1a). Approaching the Strait of Sicily, the AC branches north into the Tyrrhenian Sea and southeastward into the Strait of Sicily (e.g., Font et al., 1998; Poulain et al., 2012).

Downstream of the Strait of Sicily, the freshwater transport in the Ionian Sea is complex and follows multiple pathways. For simplification, it is shown by the dashed arrow in Fig.1c which indicates the Atlantic-Ionian stream. Finally, the eastward flow of the MAW enters the Levantine 
Basin, where it splits into the Mid-Mediterranean Jet (MMJ) and the coastal Libyo-Egyptian Current (LEC, Alhammoud et al., 2005; Menna et al., 2012). Although the MMJ could be a result of eddy aliasing (Alhammoud et al., 2005; Millot and Gerin, 2010), we include it into our simplified circulation scheme (Fig. 1c) because it is evident in mean sea level data (e.g., Rio et al., 2007). In this scheme, the MMJ and LEC are shown as two major eastward branches of cyclonic circulation of the Levantine Basin. The major returning westward flow is known as the Asia Minor Current (AMC), which flows along the southern Turkish coast. The eastward transport of the MAW reaches the easternmost part of the Mediterranean generally flowing along southern coastal regions of the basin. This transport explains the presence of large scale eastward and northward Mediterranean SSS gradients (see Fig.1a). While SSS of the Atlantic Water entering through the Strait of Gibraltar is about 36.15 psu, the MAW in the Levantine Basin is saltier by about 2.5 psu (38.6 psu, see Ozsoy et al., 1989).

The actual circulation of the Mediterranean Sea is more complex than this schematic view due to the diverse regional coastlines, islands, and bathymetry (e.g., Poulain et al., 2012). Its temporal variability is still poorly understood because of a lack of regular observations. Model simulations (Demirov and Pinardi, 2002) suggest a consistent response of the MAW transport to shifts in regional wind regimes. Although most of major Atlantic atmospheric patterns have an impact on winds over the Mediterranean region (Josey et al., 2011), the prime switch in the atmospheric circulation is associated with anomalous winds around the southern atmospheric pressure pole of the North Atlantic Oscillation (NAO) pattern. Strengthening of the southern pole leads to increased easterlies (weaker winds, anomalous anticyclonic winds) over the Western Mediterranean and stronger westerlies (anomalous cyclonic winds) over the Eastern Mediterranean. The Demirov and Pinardi (2002) study suggests that this anomalous wind pattern leads to a weakening of the cyclonic circulation in upper levels of the Levantine Basin and related weakening in the eastward transport of the fresher MAW. This change of the circulation increases salinities by $0.2-0.3$ psu in the central Levantine Basin. It modifies the properties and amount of Levantine Intermediate Water (LIW). This is correlated with SSS change in the Levantine, in turn, related to variable MAW pathways (Myers and Haines, 2000). Furthermore, with about 13 year lag, salinity variations in the Levantine basin cause downstream salinity variations of the LIW transported westward through the Aegean and Adriatic Seas and further 
westward through the Strait of Sicily and thus impact the Western Mediterranean (Gačić et al., 2013).

Monitoring such complexity makes the Mediterranean Sea an appealing target for remote sensing research. In particular, satellite altimeter sea level data in combination with in-situ measurements allow for better quantification of the mean Mediterranean circulation (e.g., Rio et al., 2007; Poulain et al., 2012). But, the estimate of mean dynamical topography depends on the averaging period. In the Ionian Sea, there exists an apparent difference between the mean dynamic topography of Rio et al. (2007), shown in their Fig. 11 and that shown in Fig. 1c, which is based on longer data through early 2019. In fact, an Empirical Orthogonal Function (EOF) analysis of sea level reveals an important variability pattern concentrated in the Ionian Sea known as the Adriatic- Ionian Bimodal Oscillation System, BiOS, (Gačić et al., 2011) also noted by Borzelli et al. (2009). This sea level pattern plays a role in regulating the intensity of MAW transport into the eastern Mediterranean. During a negative BiOS phase, the Ionian circulation is cyclonic and the eastward MAW flow accelerates and intensifies. During a positive BiOS phase, the Ionian circulation switches to anticyclonic that increases the spreading of MAW northeastward and freshens the northwestern Ionian Sea. In this case, the MAW pathway is longer and weaker. Thus, the Levantine gets less dilution by MAW during the anticyclonic, positive BiOS phase, which explains positively correlated variations of BiOS amplitude and eastern Mediterranean SSS. See also a nice scheme of the BiOS mechanism in Fig. 12 from Malanotte-Rizzoli et al. (2014). Levantine-wide salinification due to a weaker/saltier inflow of the MAW is in line with model simulations of Demirov and Pinardi (2002) and Ciappa (2014). BiOS-induced multi-year changes in Levantine basin salinity are superimposed on longer term salinification trend estimated as $0.008 \mathrm{psu} /$ year (Ozer et al., 2017).

Despite newly available satellite remote sensing salinity for this region, its potential application in the Mediterranean, especially the eastern part, remains widely unexplored. While regional SSS products focusing on the western Mediterranean have been recently released (Isern- Fontanet et al., 2016; Olmedo et al., 2018), the eastern Mediterranean is still a challenging area for L-band salinity retrieval. Normally high errors in satellite SSS are present over cold, polar waters, where radiometric sensitivity to salinity is low (e.g., Meissner et al., 2016). But, as we'll see later, high SSS errors are locally present over relatively warm Mediterranean waters. Although the exact 
nature and magnitude of these regional errors have not been quantified yet, they are attributed to a combination of land contamination (due to multiple islands and complex coastal line) and high level of regional radio frequency interference. These artifacts have stronger impacts on salinity retrievals from the European Space Agency Soil Moisture Ocean Salinity (SMOS) mission, which employs an interferometric L-band radiometer (Reul et al., 2014), than on those from the NASA Soil Moisture Active Passive (SMAP) mission.

In this paper, we focus on SMAP SSS data to investigate changes in the thermohaline properties of the Levantine Basin that occurred during SMAP observation period since April 2015. We also compare SMAP SSS data against regional in-situ observations. Although satellite retrieval errors are normally below 0.2 psu over open ocean warm waters (e.g. Lee, 2016), such data should be used with a caution in areas with high radio frequency interference as well as approaching continents and islands where land signal leakages through side lobes of satellite radiometer antenna imprint on retrieved SSS (e.g., Kao et al., 2018). The above factors are regionally present in the Mediterranean. Our intention is to show that, despite strong regional biases, Mediterranean geophysical signals are nevertheless present in satellite SSS fields. To infer these signals we rely on a de-seasoning procedure, which eliminates the real seasonal cycle along with the seasonally dependent bias, which is present in satellite SSS retrievals (Meissner et al., 2016). Then we focus on periods of monotonic changes in near-surface salinity (based on Argo float examination). It appears that almost the entire SMAP observation period is majorly coincident with the recent period of eastern Mediterranean salinification since 2016. This allows focussing on the mean tendency of satellite SSS during this period, which further smooths remaining errors present in instantaneous SSS snapshots. This extra smoothing allows revealing a pattern of salinity changes associated with changing Ionian Sea circulation regime associated with the BiOS pattern.

Although the spatial distribution of SSS changes derived from satellite data has better spatial resolution, its magnitude is larger than that based on in-situ data. Comparisons against in-situ Argo data indicates the presence of an area averaged temporal component in SMAP SSS bias, especially noticeable over the eastern Mediterranean. The latter should be subtracted from area averaged SMAP tendency estimates in the east that allows making them more consistent with the corresponding salinification tendency obtained from the binned Argo. The new information 
delivered by satellite SSS provides a better spatial delineation of these salinity change patterns. In these ways, satellite SSS compliments the existing in-situ observation systems which have better accuracy but limited spatial and temporal resolution.

\section{Data}

Satellite SSS: All satellite SSS data are obtained from the Soil Moisture Active Passive (SMAP) mission. Global SMAP SSS is provided daily as an 8-day running mean on a $0.25^{\circ}$ spatial grid (Version 3 as produced by the Remote Sensing Systems (www.remss.com/missions/smap; doi: 10.5067/SMP30-3SPCS; Meissner et al., 2018). The surface footprint of each measurement is $39 \times 47 \mathrm{~km}$ so the gridded data are oversampled and the effective resolution is close to $40 \mathrm{~km}$.

For this study, the data were averaged monthly. Although satellite SSS agrees with in-situ data in the open sea, its accuracy approaching coasts is less certain due to several limitations that lead to seasonally dependent biases (Meissner et al., 2016). In particular, SMAP comparison against coastal in situ thermosalingraph salinity data shows a significant bias in absolute SSS coastward of $\sim 0.2 \%$ antenna land contamination factor provided in the SMAP data (Grodsky et al., 2018), which occupies a significant portion of the basin. The land-impacted SSS bias is seasonally dependent due to seasonal changes in terrestrial microwave properties (soil moisture, in particular). Fortunately, it has been shown that SSS anomalies, i.e. the SSS difference computed relative to a monthly satellite SSS climatology, can effectively remove such seasonal salinity biases, but along with the real seasonal cycle (Boutin et al., 2016; Lee, 2016). For this study, the monthly seasonal cycle at each pixel was estimated as the time mean for each calendar month (based on the entire SMAP period, April 2015 - onward). Previous work (Boutin et al., 2016; Lee, 2016) has suggested that satellite-based observations of monthly anomalies in SSS from SMOS and AQUARUIS missions, as defined above, have better accuracy and applicability to extend nearer to the coasts. This assumption will be evaluated against Mediterranean Argo float and buoy data.

Mooring data: In the Mediterranean, there are a number of salinity measuring moorings along Spanish coasts (http://www.puertos.es/en-us/oceanografia/Pages/portus.aspx ) and only two currently operational buoys of the M3A network (Nittis et al., 2007). The latter two are located in the eastern basin north of Create, E1M3A, (Fig. A1a) and in the northern Ligurian Sea of the western basin, W1E3A. Data are available from the Ocean Sites at 
ftp://ftp.ifremer.fr/ifremer/oceansites/DATA/. All these buoys are located close to land that complicates satellite-buoy comparisons due to land signal leakages through side lobes of SMAP radiometer antenna. At all Spanish coast buoy locations, the SMAP land contamination factor is very strong $(L C>2 \%)$. At the western M3A buoy location (W1E3A), the land contamination factor is also strong, $L C \approx 2 \%$. Because SMAP grid points with such strong $L C$ are not recommended to use (Meissner private communications), the satellite-buoy comparison is conducted only at the eastern M3A buoy (E1M3A) where $L C \approx 1 \%$. There are a number of other buoys in the region, but they locate too close to the land to be used for microwave satellite data validation.

Argo data: The primary in situ SSS proxy for this study is constructed using shallowest-level Argo float salinity measurements $(5-10 \mathrm{~m})$ that are binned onto a daily $1^{\circ} \times 1^{\circ}$ grid without any attempt to fill gaps. Original Argo profile data (https://doi.org/10.17882/42182) are available from multiple web sites, including ftp://usgodae.org/. For comparison to this product, we also use the vertically-resolved Scripps Institution of Oceanography analysis that is also based solely on Argo data. This analysis decomposes data into climatological mean and monthly anomaly fields computed over the analysis period from January 2004-present (http://sioargo.ucsd.edu/RG_Climatology.html). It is available monthly on a $1^{\circ} \times 1^{\circ}$ grid (Roemmich and Gilson, 2009). As a proxy for SSS, the shallowest level salinity is used for each analysis, from which anomalies are calculated by subtracting the corresponding monthly seasonal cycle computed over the analysis period from January 2004-present.

Thermosalinigraph (TSG) data: For ground truth validations, the following 3 types of TSG nearsurface salinity data are used. The first dataset is the Laboratoire d'Études en Géophysique et Océanographie spatiales delayed mode (LEGOS-DM) dataset, derived from TSG installed on voluntary observing ships. It is collected, validated, archived, and made freely available by the French Sea Surface Salinity Observation Service, http://sss.sedoo.fr/, (Alory et al., 2015). The second dataset is the Global Ocean Surface Underway Data (GOSUD) TSG data from research vessels. It is derived from French research vessels that have been collecting TSG data since early 2000 in contribution to the GOSUD program. This set of homogeneous instruments is permanently monitored and regularly calibrated. Water samples are taken on a daily basis by the crew and later analyzed in the laboratory. The careful calibration and instrument maintenance, 
complemented with a rigorous adjustment based on water samples, allows reaching an accuracy of a few tenths of psu in salinity. This delayed mode dataset (Kolodziejczyk et al., 2015) is updated annually and freely available from the SMOS Pilot-Mission Exploitation Platform, PiMEP, (https://pimep.oceandatalab.com). The last TSG dataset is the GOSUD-Sailing-ship salinity obtained from voluntary sailing ships using medium or small size salinity sensors (https://doi.org/10.17882/39476). These data complement the network installed on research vessels or commercial ships. This delayed mode dataset (Reynaud et al., 2015) is updated annually as a contribution to the GOSUD program and is freely available from the Pi_MEP. For all TSG datasets, only good and adjusted TSG data with quality flags $=1$ and 2 are used.

AVISO sea level: The monthly AVISO multi-satellite merged absolute dynamic topography and its related geostrophic currents are used to identify regional sea circulation dynamics. These satellite altimeter data products are available since 1993 and distributed through the Copernicus Marine Environment Monitoring Service (http://marine.copernicus.eu).

Other satellite data: Gridded 10m near-surface winds from the ASCAT scatterometer onboard the European Meteorological Satellite Organization MetOp satellites are described in Bentamy and Croize-Fillon (2012) and available at (ftp.ifremer.fr/ifremer/cersat/products/gridded/MWF/L3/ASCAT). Institut Francais pour la Recherche et l'Exploitation de la Mer (IFREMER Version 4) satellite sea surface turbulent fluxes (Bentamy et al., 2017) are available on a $0.25^{\circ} \times 0.25^{\circ}$ grid from the European Space Agency (ESA) Ocean Heat Flux project (OHF, www.oceanheatflux.org). Finally, we evaluate precipitation using the NASA Tropical Rainfall Measuring Mission multi-satellite daily combined microwave and infrared data analysis on a $0.25^{\circ} \times 0.25^{\circ}$ grid (TRMM_3B42 version 7) described in Huffman et al. (2010) and available at https://disc.gsfc.nasa.gov/datasets?keywords=TRMM_3B42_Daily_V7 ).

Other data: The time mean evaporation minus precipitation (E-P) and its long term tendency during satellite altimetry epoch since 1993 are characterized using monthly total precipitation and evaporation obtained from the ERA-Interim reanalysis of atmospheric parameters produced by the ECMWF (Dee et al., 2011). The ERA-Interim data used in this study are monthly averages on a $1^{\circ} \times 1^{\circ}$ grid available since 1979 at https://apps.ecmwf.int/datasets/data/interimfull-mnth/levtype $=$ sfc/. 
Collocation procedure: Satellite-insitu SSS data collocation is performed on the Pi-MED platform. For daily SMAP SSS data that have approximately $40 \mathrm{~km}$ ground resolution, the system collects all satellite data within 12 hour/20km search radius of an insitu observation.

\section{Results}

During the SMAP period (currently 04/2015-02/2019), the Mediterranean Sea displays notorious, almost 3-year long monotonic changes in SSS (Fig. 2a). Regardless of the relatively short SMAP period, these SSS changes display important spatial patterns. They are weaker west of the Sicilian Strait and amplified in the eastern Mediterranean. The strongest salinification at an area average rate of $0.22 \pm 0.03 \mathrm{psu} /$ year occupies the Levantine Basin where the mission long change reaches $\sim 0.5$ psu (see Fig. 2 a for the Levantine basin index area). Satellite-derived salinification rate is stronger than salinification rates obtained from the binned Argo $(0.12 \pm$ $0.02 \mathrm{psu} / \mathrm{year})$ and the smoothed objectively analyzed Argo (0.06 psu/year), a discrepancy that will be discussed later. Levantine salinification is accompanied by two important upstream areas where salinity increases along the coast of Libya and decreases in the northwestern Ionian Sea (Fig. 2a). Although trend patterns inferred from satellite SSS and binned Argo show similar basin-wide sign distributions, the magnitude of a positive trend is overestimated in the eastern Mediterranean (Figs. 2a,b). This is a consequence of the spatial pattern of satellite bias (Fig. 2c) that also has a temporal component $(0.08 \pm 0.02 \mathrm{psu} / \mathrm{year})$ in the eastern Mediterranean as will be seen later in Fig. A2. Due to the non-negligible impact of land emission on sea water salinity retrieval, SMAP SSS has a significant negative bias that is stronger and locally reaches -1 psu in the eastern Mediterranean (Fig. 2c). To mitigate possible impacts of this bias, all estimates of salinity changes are based on monthly anomalies, which (as discussed in the Data section) are expected to be more accurate than absolute salinities. After filtering out apparent SMAP SSS outliers (out of 35 - 40 psu range), the RMS difference between absolute monthly SMAP SSS and binned Argo near-surface salinity averaged over western part $\left(<15^{\circ} \mathrm{E}\right)$ and eastern part $(>$ $15^{\circ} \mathrm{E}$ ) of the Mediterranean is 0.47 and 0.9 psu while that for salinity anomalies is 0.3 and 0.31 psu, respectively.

Qualitatively, the spatial distribution of SSS tendency (Fig. 2a) is confirmed by Argo data in Fig. $2 \mathrm{~b}$ that shows both the positive tendency in the Levantine basin and the opposite tendency in the northwestern Ionian Sea. Although the time series of SSS averaged over the Levantine basin 
index area (see Fig. 2a for the index area) show satellite SSS about 0.5 psu fresher than in-situ data (Fig. 3a), as expected from Fig. 2c, the size of the anomaly magnitude is consistent for satellite and in-situ data during the salty period since 2017. Prior to that (especially before August 2016) SMAP fresh anomaly is apparently stronger than that based on the binned Argo (Fig. 3b) that may be potentially caused by a portion of time varying radio frequency interference signal that wasn't detected by SMAP sensors. Because the fresh SMAP SSS bias is especially strong during the early period of SMAP observations before August 2016, the SSS tendency estimated based on the entire SMAP period (Fig. 2a) is compared to the SSS tendency estimated over the period excluding these earlier data (see Appendix), both of which show qualitatively similar patterns (Figs. A3a,b).

Estimates of the temporal component of SMAP bias (see Appendix) show that its spatial averages have different behavior in the eastern and western Mediterranean (Fig. A2), which may originate from the corresponding temporal changes in the magnitude of radio frequency interference. There is virtually neither time mean SMAP SSS bias nor its temporal tendency in the west. In contrast, in the east, both are present with the time mean bias of $\approx-0.5 \mathrm{psu}$ (in line with Fig. 2c and satellite-buoy comparisons in Fig. A1b) and the temporal tendency of $0.08 \pm$ $0.02 \mathrm{psu} / \mathrm{year}$. For comparisons with in-situ measurements, the latter should be subtracted from area averaged SMAP tendency estimates in the east. Correcting the SMAP salinification tendency spatially averaged over the Levantine basin index area, $0.22 \pm 0.03$ psu/year (Fig. 2a, $3 b)$, for the above bias tendency gives the corrected Levantine basin salinification tendency, $0.14 \pm 0.04 \mathrm{psu} / \mathrm{year}$, that is more consistent with the area averaged salinification tendency obtained from the binned Argo (0.12 $\pm 0.02 \mathrm{psu} /$ year).

SMAP and binned Argo records show an apparent salinification of the Levantine since 2016 associated with the switch from a fresh state prior to 2017 to an above normal salinity state in and after 2017 (Fig. 3b). The magnitude of the recent salinification exceeds previous events since 2004. Due to the paucity of Argo data, in situ records based on the binned Argo have multiple gaps in the Levantine domain (Fig. 3b, see also Fig 2a for the domain box). Prior to 2017, negative SMAP SSS anomaly is apparently larger in magnitude by $\sim 0.2$ to 0.3 psu (Fig. $2 b$ ) than Argo-based salinity anomaly. The 2015-16 fresh bias in SMAP SSS is not related to ARGO data coverage. This is indirectly illustrated by supplementary Fig. S1 that shows that 2015-16 Argo 
data coverage was even better than in the following years. Continuous spatial and temporal coverage is provided by the objective Argo profile analysis (Fig. 3c) that shows salinity anomalies mostly confined to the upper $150 \mathrm{~m}$. These objectively analyzed data also confirm the larger magnitude of the recent Levantine salinification in comparison with previous events, but with a size of about half of those observed by SMAP and deduced from the binned Argo data. Such a discrepancy is expected given that objective analysis techniques attenuate anomalies where data are missing.

Fig. 3b shows that temporal variations of the Levantine SSS from binned Argo are positively correlated with BiOS amplitude, corr $=0.65_{0.56}^{0.74}$, (the $95 \%$ confidence interval is shown as subscripts). Temporal correlation with SMAP SSS has the similar size, $\operatorname{corr}=0.64_{0.36}^{0.82}$, but the larger $95 \%$ confidence interval because the latter correlation is estimated from significantly shorter time interval. As explained in Gačić et al. (2011) and illustrated in Malanotte-Rizzoli et al. (2014), the reason for these in-phase variations is related to periodic switches in Ionian Sea circulation regime between anticyclonic (positive BiOS, Fig. 3d) and cyclonic (negative BiOS) cases. During negative BiOS, the direct zonal freshwater transport amplifies in the southern Ionian Sea that leads to stronger transport, shorter transport time and weaker modification of the MAW. These result in larger volume and fresher salinity of the MAW entering the eastern Mediterranean through the Cretan Passage. In contrast, during a positive BiOS phase, a larger portion of MAW flow exiting the Strait of Sicily turns northeastward and circulates anticyclonically in the Ionian Sea, decreasing local salinity there (Figs. 1a, 2a). This also increases MAW travel time to the Cretan Passage and thus increases SSS due to longer exposure to evaporative flux. The sea level pattern in Fig. 3d also indicates that eastward transport through the Cretan Passage increases/decreases during negative/positive BiOS phases, respectively. Hence, the switches in the Ionian Sea circulation regime modulate the volume and properties of the freshwater transport into the eastern Mediterranean and thus impact its thermohaline properties (Fig. 3b).

Besides the freshwater transport modification by the Ionian Sea BiOS pattern that affects salinity of water entering the eastern Mediterranean and thus induces salt transport anomaly associated with mean currents acting on anomalous salinity (termed as $u S^{\prime}$ factor), the model simulations presented in Demirov and Pinardi (2002) suggest the presence of atmospheric forcing driven 
response with significant changes in the structure of circulation within the Eastern basin that induces anomalous salt transport associated with anomalous currents acting on mean salinity (termed as $u^{\prime} S$ factor). Besides the latter, wind variations may affect salinity through their impact on the surface freshwater flux. The primarily mode of Mediterranean wind variations is reflected in the leading multivariate EOF of anomalous monthly wind, evaporation, and precipitation (Fig. 4a). This mode of atmospheric variability reflects anomalous wind circulation around the southern pole of the NAO pattern. Its strengthening amplifies easterlies (weaker wind and anomalous anticyclone) over the Western Mediterranean and stronger westerlies (stronger wind and anomalous cyclone) over the Eastern Mediterranean. These zonal wind changes define a mostly zonal anomalous evaporation pattern with higher evaporation in the east (Fig. 4b). Although the net atmospheric freshwater flux, $E-P$, is strongly influenced by decreased precipitation in the north, the major east-to-west dipole is still present with an area average east Mediterranean evaporation-minus-precipitation anomaly of $\delta(E-P) \approx 0.3 \mathrm{~mm} /$ day. Assuming local balance between salinity rate of change and normalized net freshwater flux anomaly, $\partial S / \partial t=(E-P) S / D$, such extra evaporation would change the mixed layer salinity by, $\Delta S=$ $\delta(E-P) \cdot S / D \cdot \Delta t=0.1 \mathrm{psu}$, if acting on an $D=100 \mathrm{~m}$ deep mixed layer (Fig. 3c) over $\Delta t=3$ year-long SMAP period. Such a magnitude of flux-induced salinity change is not negligible when compared with the total observed salinity variations (Fig. 3b).

Next, the focus is on the temporal variability of the atmospheric (ATM) forcing and its possible interplay with the BiOS. Visual inspection of amplitudes associated with the two modes suggest a weak anti-correlation (Fig. 4d). But the maximum magnitude of the lagged correlation between the two is only -0.25 and corresponds to the BIOS leading the ATM by a few months (not shown). This, in turn, suggests that this BiOS mode is probably not atmospherically driven. The most notorious sporadic anti-correlation of the two modes occurs in 2011-12 (Fig. 4d) and may contribute to weaker eastern freshening than 2017-18 salinification despite the similar magnitude of the BiOS (Figs. 3b, c).

Despite its primary influence on the eastern Mediterranean freshwater transport, the BiOS (Fig. $3 \mathrm{~d}$ ) is only the second EOF mode that accounts only for about 7\% of anomalous Mediterranean sea level variance over 1993-2018. The explained variance is smaller than in Gačić et al. (2011) where a modified EOF analysis was applied (see details therein). The relatively small explained 
variance in standard EOF analysis is attributed to the spatial concentration of the BiOS mode in the Ionian basin that leads to the relatively small basin-wide explained variance. The leading mode of anomalous sea level (Figs. 5c,d) accounts for in-phase basin wide sea level variations and explains about $40 \%$ of the variance (the linear sea level rise tendency is removed). Temporal variations of this leading EOF display an apparent link with temporal variations of the atmospheric forcing (Fig. 5d).

Altimetry epoch linear sea level tendency (Fig. 5a), which was subtracted from sea level EOF analysis in Fig. 5, shows a basin-wide increase with an area-averaged rate of $\sim 2.6 \mathrm{~mm} /$ year. This rate is below the global ocean mean rate of $\sim 3.3 \mathrm{~mm} / \mathrm{year}$, possibly due to the impact of net evaporation. The spatial pattern is not homogeneous with a weaker rate of less than $1 \mathrm{~mm} / \mathrm{year}$ over the Ionian Sea and adjacent areas roughly corresponding to the BiOS pattern. The weakening trend of the BiOS pattern suggests a gradual increase in freshwater transport into the eastern Mediterranean. Despite this increase, the eastern Mediterranean gets saltier, especially in recent decades (e.g. Iona et al., 2018). This is perhaps due to the dominating impact of strengthening $E-P$ (Mariotti, 2010). But, the characteristic magnitude of $E-P$ tendency (derived from 1993-onward ERA-Interim data) is only about 0.1 (mm/day)/decade (Fig. 5b) that's is not significant in comparison with the time mean $E-P$ of a few mm/day (Fig. 1b).

On shorter time scales, there is an apparent co-variability of sea level and winds (Fig. 5d). A few months long sea level variations occur in-phase over the entire Mediterranean with a characteristic magnitude of a few centimeters (Fig. 5c). The temporal correlation between amplitudes of ATM and sea level EOFs (not shown) peaks at zero lag with a magnitude of $\sim 0.55$. Although the presence of such correlation is in line with previous research (e.g. Tsimplis, 2005; Martínez-Asensio et al., 2014), it is still intriguing as per which effects may induce such net changes in the Mediterranean water volume. In part, they may originate from Mediterraneanwide changes in $P-E$. Basin-average changes in $P-E$ are about $0.02 \mathrm{~cm} /$ day in magnitude (Fig.4c). They are forced primarily by precipitation changes in the north, while the evaporationonly average is about three times weaker. If acting for about 3 months, such basin-average $P-E$ anomaly would change the mean sea level by $2 \mathrm{~cm}$, which corresponds to the basin-average EOF magnitude in Fig. 5c. The whole basin should adjust quickly to local net-evaporation-forced sea level anomalies through the ocean barotropic adjustment. If the sea level rate of change was 
balanced by the $P-E$ only, $\partial \zeta / \partial t \sim(P-E)$, it would imply a quadrature phase relationship between sea level and $P-E$ variations (sea level variation lags $P-E$ variation by $\pi / 4$ ). Hence, surface net evaporation induced sea level variations should be in quadrature rather than in-phase with atmospheric variations, in contrast to what is seen in Fig. 5d.

The spatial pattern of the leading EOF also reflects a basin-wide east-to-west pressure gradient that balances anomalous zonal wind stress (see Figs. 5c, 4a). Besides the above features, the leading EOF doesn't display any features suggesting a consistent response of geostrophic circulation to wind forcing. Perhaps, this observation suggests that circulation response is highly variable and mostly eddy-driven (e.g., Millot and Taupier-Letage, 2005), which is averaged out by an EOF analysis. Some weak response is present in the AC (Fig. 1c) where the negative sea level anomaly along African coast suggests somewhat weaker eastward freshwater flow consistent with local westward wind anomaly (Figs. 5c, 4a).

The close temporal correlation between the Levantine salinity and the BiOS amplitude (Fig. 3b) illustrates the primarily impact of the latter on the Eastern Mediterranean salinity. But similarly strong BiOS events cause different magnitudes of salinity events. In particular, the recent eastern salinification is apparently stronger than previous events since 2004 (see e.g., Fig. 3c that is based on Argo only). Such deviations may be attributed to anomalous winds and their impact on local evaporation and currents. Next, we focus on particular changes in the circulation during the 2015-onward eastern salinification period. As noted above, this period coincides with an increase in BiOS amplitude (Fig. 3b) that suggests that saltier water passes eastward through the Cretan Passage after a longer journey across the Ionian Sea. Additionally, the Demirov and Pinardi (2002) simulations suggest a weakening of cyclonic circulation and $\sim 0.2$ psu salinification in the eastern Mediterranean in response to wind anomalies corresponding to positive phases of the atmospheric EOF (Fig. 4a). One can observe positive ATM anomalies corresponding to this pattern were strengthening at least during 2015-2017 with particularly strong spikes in December of 2015 and 2016. Although the observed changes in the circulation (Fig. 6) cannot be attributed firmly to the changes in wind forcing, their spatial pattern is consistent with the Demirov and Pinardi (2002) simulations. 
To assess these circulation changes, we compute the linear temporal tendency (2015-onward) of anomalous geostrophic velocity components at each grid point. Comparing to the time mean geostrophic circulation (Fig. 6a), the circulation changes (Fig. 6b) show an accelerated freshwater transport south of Sicily and into the western Ionian Sea (a part of the BiOS pattern). This likely causes the fresh salinity anomaly there (Figs. 2a,b). Along with this northward deflection, the eastward transport weakens along the southern Strait of Sicily bringing less freshwater into the Libyan Basin. This may cause the salinification tendency seen in Fig. 2a. Interestingly, there are no or weak changes in the Algerian Current. In the eastern Mediterranean, the circulation tendency is consistent with a general weakening of the local cyclonic circulation (compare Figs. 6a,b). This includes a weakening of the eastward transport along the southern Cretan Passage that extends further east into the LEC along Libya and Egypt coast. The weakening coastal transport is also accompanied by a weakening in the mid-basin MMJ. As expected, weaker eastward freshwater transport into the eastern Mediterranean is accompanied by a weaker return westward flow in the AMC along the southern coast of Turkey and further west of Create. Overall, the observed changes in the circulation of the central and eastern Mediterranean suggest that the strong recent salinification in the east may be a cause of combined forcing, including the strengthening of anticyclonic circulation in the Ionian Sea (the BiOS pattern) and the strengthening of winds corresponding to enhanced NAO atmospheric pressure pattern. The impact of wind forcing is twofold and includes stronger evaporative losses (Fig. 4b) as well as weaker cyclonic currents (Fig. 6b) in the eastern Mediterranean.

\section{Summary}

The Levantine basin experiences periodic changes in the upper layer salinity that are primarily related to changes in the circulation of the Ionian Sea and related changes in the thermohaline properties and volume of eastward freshwater transport along the Cretan Passage (Gačić et al., 2011). New satellite capabilities of remote sensing salinity augment in-situ observations and provide an enhanced spatial description of basin-wide changes in the surface salinity. Although absolute values of satellite-derived SSS in the Mediterranean region are still biased due to challenges imposed by land emission contamination and radio frequency interference, this analysis shows that satellite SSS anomalies are sufficiently accurate to allow examination of spatial patterns and time-variable SSS. In particular, the satellite SSS anomaly time series from the Soil Moisture Active Passive (SMAP) mission indicates a steady salinification of the eastern 
Mediterranean Levantine Basin at a rate of $\sim 0.22$ psu/year during 2015-2018 that is accompanied by a corresponding freshening in the western Ionian Sea. This eastern basin salinification tendency estimate is partially contaminated by temporally varying satellite salinity bias component (estimated as about $0.08 \mathrm{psu} / \mathrm{year}$ ), which probably originates from temporal variations of radio frequency interference unaccounted by SMAP sensors. After subtraction of this spurious SMAP SSS tendency, the final estimate of Levantine Basin salinification drops to $\sim 0.14 \mathrm{psu} / \mathrm{year}$ that is more consistent with salinity tendency estimate derived from in-situ (binned Argo) data ( 0.12 psu/year). Although a spatial pattern of eastern Mediterranean salinity change is expected from circulation changes induced by the Adriatic- Ionian Bimodal Oscillation System (BiOS), the satellite data provide a new spatial/temporal perspective. Results suggest that monthly satellite SSS anomaly mapping in this region can augment the existing regional observing system and support future circulation model interpretation.

Both satellite and in-situ observations indicate that the recent (2015-onward) salinification tendency in the Levantine Basin is stronger than previous episodes despite the similar magnitude of the forcing BiOS sea level pattern. Although the BiOS pattern is not produced by wind forcing, changes in recent years were characterized by both a positive BIOS tendency and a positive wind tendency corresponding to enhancing NAO atmospheric pressure pattern. The latter wind variations may have caused the weakening cyclonic circulation of the eastern Mediterranean that is seen in the satellite altimeter data. Overall, the observed changes in the circulation of the central and eastern Mediterranean suggest that the strong recent salinification in the east may be a superposition of the strengthening of anticyclonic circulation in the Ionian Sea (the BiOS pattern that leads to decreased freshwater transport across western boundary the Levantine Basin) and the strengthening of local winds corresponding to enhanced southern pole of the NAO atmospheric pressure pattern. The impact of the strengthening wind forcing tendency is twofold and includes the strengthening of evaporative losses (Fig. 4b) as well as the weakening of cyclonic currents (Fig. 6b) in the eastern Mediterranean.

\section{Appendix.}


This Appendix focuses on SMAP-buoy comparisons, estimates of the temporally varying component in satellite SSS retrieval bias, and sensitivity of salinity tendency estimates to a particular choice of the reference time period.

The de-seasoning procedure is illustrated by comparisons of in-situ data from a buoy in the eastern Mediterranean (E1M3A) collocated with SMAP data using $1^{\circ} / 1$ day search radius (Fig. A1). Although there are two currently operational buoys of the M3A network (Nittis et al., 2007), both locations are very close to the coast (Fig. A1a) that complicates satellite-buoy comparisons due to land signal leakages through side lobes of SMAP radiometer antenna. At the western buoy location (W13MA), the land contamination factor is particularly strong, $L C \approx 2 \%$. Because SMAP grid points with such strong $L C$ have abnormally high noise (Meissner private communications), the satellite-buoy comparison is conducted only at the eastern buoy location where $L C \approx 1 \%$. As a proxy for in-situ SSS, buoy salinity averaged in the upper $20 \mathrm{~m}$ column of water is used. This is dictated by buoy data availability. When both, $z<5 \mathrm{~m}$ and $z=20 \mathrm{~m}$ buoy salinity data are available, they differ by $<0.1$ psu. Both, in-situ and satellite SSS show a gradual increase in SSS during the SMAP period since April 2015 (Fig. A1b). For each record, this gradual salinification is seen as the difference from the corresponding repeating seasonal cycle of SSS. At this southern Aegean Sea location, the seasonal cycle is pronounced, but apparently different for in-situ and SMAP data, which is a consequence of the presence of a seasonally dependent bias in SMAP SSS retrievals. Besides differences in annual phase and seasonal magnitude, SMAP SSS also has a time mean bias component of $\sim-0.5$ psu that dominates the root mean square error (RMSE) versus in-situ data (Fig. A1b). The RMSE is decreased by a factor of two (RMSE=0.24 psu) after subtracting the seasonal cycle (Fig. A1c). While, for in-situ data, this de-seasoning procedure simply removes the observed seasonal cycle, for SMAP data, it removes both the real seasonal cycle and the seasonally-dependent bias component. The salinification tendency becomes clearer in SSS anomaly data (Fig. A1c). Its magnitude differ for in-situ (0.07 $\pm 0.02 \mathrm{psu} /$ year $)$ and SMAP $(0.17 \pm 0.04 \mathrm{psu} /$ year $)$ if all data are used. If only data after 2016 are used, the SSS tendency estimates for in-situ $(0.08 \pm 0.02$ psu/year) and SMAP (0.09 $\pm 0.06 \mathrm{psu} / \mathrm{year})$ roughly converge, but SMAP-based estimate has larger uncertainty due to satellite data noise (Fig. A1c). SMAP and in-situ SSS tendency 
estimates converge due to the elimination of earlier SMAP data with stronger negative bias associated with an unaccounted portion of the radio frequency interference (RFI).

The anticipated impact of the RFI has spatially and temporally varying components. Due to weak in-situ data coverage, the two can't be evaluated simultaneously based on observations. The spatial pattern of this bias is illustrated in Fig. 2c, which is conditionally separated into two regions with differing magnitudes of the RFI-related bias. The bias is relatively weak in the western Mediterranean (west of $15^{\circ} \mathrm{E}$ ) and is apparently negative in the central and eastern Mediterranean (east of $15^{\circ} \mathrm{E}$ ) where SSS normally exceeds 38 psu (Fig. 1a). Because at above $38 \mathrm{psu}$, the sea water dielectric models are all pretty much based on extrapolation (Meissner and Wentz, 2004), the dielectric model errors could potentially add up to the negative SMAP SSS in the eastern Mediterranean. Temporal variations of the bias spatially averaged over these two regions show different behavior (Fig. A2). While the time mean SMAP SSS bias component and its temporal tendency component are relatively weak in the west, both bias components are apparent in the east. Here, the time mean bias is $\approx-0.5$ psu (in line with Fig. $2 \mathrm{c}$ and Fig. A1b) and the temporal tendency is $0.08 \pm 0.02 \mathrm{psu} / \mathrm{year}$. The latter bias component is probably associated with temporally changing RFI level and leads to a spurious component in satelliteobserved SSS tendency. For comparisons with in-situ data, this spurious tendency should be subtracted from area averaged SMAP tendency estimates. Correcting the original SMAP salinification tendency spatially averaged over the Levantine basin index area $(0.22 \pm 0.03$ psu/year) (Fig. 2a, 3b) for the above bias tendency gives the corrected tendency $(0.14 \pm 0.04$ $\mathrm{psu} / \mathrm{year}$ ) that is more consistent with the area averaged salinification tendency obtained from the binned Argo (0.12 $\pm 0.02 \mathrm{psu} /$ year $)$.

Because the fresh SMAP SSS bias (probably associated with the RFI) changes in time and is especially strong during the early period of SMAP observations before August 2016, the SSS tendency is estimated based on the entire SMAP period (Fig. 2a) and the period excluding these earlier data (Fig. A3). Both estimates show qualitatively similar spatial patterns, including the eastern Mediterranean salinification and the northwestern Ionian Sea freshening. Surprisingly, exclusion of these earlier data has a little impact on eastern Mediterranean salinification tendency estimate, but the shorter term estimate has apparently stronger small scale noise (Figs. A3a,b). Note that Fig. A3b is the same as Fig. 2a and is included here for comparisons. Although 
the objectively analyzed (OI) Argo data generally confirm the salinification in the Levantine Basin, its magnitude is about two times weaker than in the SMAP (Fig. A3). This difference is attributed to relatively low Argo data coverage (Fig. S1) that forces OI fields to relax towards the climatology that, in turn, causes an underestimation of OI anomalies. In addition, the availability of relatively long Argo time series (in comparison with SMAP timeseries) also allows testing the sensitivity of salinity tendency estimates to a particular choice of the climatological mean. Comparisons of Ago-based salinity tendencies in Figs. A3c-f show a little change due to a switch between the Argo climatology computed over the entire dataset since 2004 and the climatology computed from shorter SMAP mission period since April 2005.

\section{Acknowledgements}

This research is supported by the NASA Ocean Salinity Science Team (OSST) grants NNX17AK08G and NNX17AK02G. All data providers are acknowledged for making their products freely available. SMAP salinity data are produced by Remote Sensing Systems and sponsored by the NASA/OSST. Argo float data were collected and made freely available by the International Argo Program, a part of the Global Ocean Observing System. Altimeter products were processed by SSALTO/DUACS and distributed by AVISO+ (https://www.aviso.altimetry.fr) with support from CNES. SSS data derived from voluntary observing ships were collected, validated, archived, and made freely available by the French Sea Surface Salinity Observation Service (http://sss.sedoo.fr). 


\section{References}

Alhammoud, B., Béranger, K., Mortier, L., Crépon, M., Dekeyser, I., 2005. Surface circulation of the Levantine Basin: Comparison of model results with observations. Prog. Oceanogr. 66, 299-320. doi:10.1016/j.pocean.2004.07.015

Alory, G., Delcroix, T., Téchiné, P., Diverrès, D., Varillon, D., Cravatte, S., Gouriou, Y., Grelet, J., Jacquin, S., Kestenare, E., Maes, C., Morrow, R., Perrier, J., Reverdin, G., Roubaud, F., 2015. The French contribution to the voluntary observing ships network of sea surface salinity. Deep Sea Res. Part I Oceanogr. Res. Pap. 105, 1-18. doi:10.1016/j.dsr.2015.08.005

Arnone, R.A., Wiesenburg, D.A., Saunders, K.D., 1990. The origin and characteristics of the Algerian Current. J. Geophys. Res. 95, 1587. doi:10.1029/JC095iC02p01587

Bentamy, A., Fillon, D.C., 2012. Gridded surface wind fields from Metop/ASCAT measurements. Int. J. Remote Sens. 33, 1729-1754. doi:10.1080/01431161.2011.600348

Bentamy, A., Piollé, J.F., Grouazel, A., Danielson, R., Gulev, S., Paul, F., Azelmat, H., Mathieu, P.P., von Schuckmann, K., Sathyendranath, S., Evers-King, H., Esau, I., Johannessen, J.A., Clayson, C.A., Pinker, R.T., Grodsky, S.A., Bourassa, M., Smith, S.R., Haines, K., Valdivieso, M., Merchant, C.J., Chapron, B., Anderson, A., Hollmann, R., Josey, S.A., 2017. Review and assessment of latent and sensible heat flux accuracy over the global oceans. Remote Sens. Environ. 201, 196-218. doi:10.1016/j.rse.2017.08.016

Borzelli, G.L.E., Gačić, M., Cardin, V., Civitarese, G., 2009. Eastern Mediterranean Transient and reversal of the Ionian Sea circulation. Geophys. Res. Lett. 36, n/a-n/a. doi:10.1029/2009GL039261

Boutin, J., Martin, N., Kolodziejczyk, N., Reverdin, G., 2016. Interannual anomalies of SMOS sea surface salinity. Remote Sens. Environ. 180, 128-136. doi:10.1016/j.rse.2016.02.053

Ciappa, A.C., 2014. The controversial path of Atlantic Water in the Eastern Mediterranean. Prog. Oceanogr. 123, 74-83. doi:10.1016/j.pocean.2014.02.001

Dee, D.P., Uppala, S.M., Simmons, A.J., Berrisford, P., Poli, P., Kobayashi, S., Andrae, U., Balmaseda, M.A., Balsamo, G., Bauer, P., Bechtold, P., Beljaars, A.C.M., van de Berg, L., Bidlot, J., Bormann, N., Delsol, C., Dragani, R., Fuentes, M., Geer, A.J., Haimberger, L., Healy, S.B., Hersbach, H., Hólm, E. V., Isaksen, L., Kållberg, P., Köhler, M., Matricardi, M., McNally, A.P., Monge-Sanz, B.M., Morcrette, J.-J., Park, B.-K., Peubey, C., de Rosnay, P., Tavolato, C., Thépaut, J.-N., Vitart, F., 2011. The ERA-Interim reanalysis: configuration and performance of the data assimilation system. Q. J. R. Meteorol. Soc. 137, 553-597. doi:10.1002/qj.828

Demirov, E., Pinardi, N., 2002. Simulation of the Mediterranean Sea circulation from 1979 to 1993: Part I. The interannual variability. J. Mar. Syst. 33-34, 23-50. doi:10.1016/S09247963(02)00051-9 
Font, J., Millot, C., Salas, J., Juliá, A., Chic, O., 1998. The drift of Modified Atlantic Water from the Alboran Sea to the eastern Mediterranean. Sci. Mar. 62.

doi:10.3989/scimar.1998.62n3211

Gačić, M., Civitarese, G., Eusebi Borzelli, G.L., Kovačević, V., Poulain, P.-M., Theocharis, A., Menna, M., Catucci, A., Zarokanellos, N., 2011. On the relationship between the decadal oscillations of the northern Ionian Sea and the salinity distributions in the eastern Mediterranean. J. Geophys. Res. 116, C12002. doi:10.1029/2011JC007280

Gačić, M., Schroeder, K., Civitarese, G., Cosoli, S., Vetrano, A., Eusebi Borzelli, G.L., 2013. Salinity in the Sicily Channel corroborates the role of the Adriatic-Ionian Bimodal Oscillating System (BiOS) in shaping the decadal variability of the Mediterranean overturning circulation. Ocean Sci. 9, 83-90. doi:10.5194/os-9-83-2013

Grodsky, S., Vandemark, D., Feng, H., 2018. Assessing Coastal SMAP Surface Salinity Accuracy and Its Application to Monitoring Gulf of Maine Circulation Dynamics. Remote Sens. 10, 1232. doi:10.3390/rs10081232

Huffman, G.J., Adler, R.F., Bolvin, D.T., Nelkin, E.J., 2010. The TRMM Multi-Satellite Precipitation Analysis (TMPA), in: Satellite Rainfall Applications for Surface Hydrology. Springer Netherlands, Dordrecht, pp. 3-22. doi:10.1007/978-90-481-2915-7_1

Iona, A., Theodorou, A., Sofianos, S., Watelet, S., Troupin, C., Beckers, J.-M., 2018. Mediterranean Sea climatic indices: monitoring long-term variability and climate changes. Earth Syst. Sci. Data 10, 1829-1842. doi:10.5194/essd-10-1829-2018

Isern- Fontanet, J., E. Olmedo, A. Turiel, J. Ballabrera- Poy, and E. García- Ladona, 2016. Retrieval of eddy dynamics from SMOS sea surface salinity measurements in the Algerian Basin (Mediterranean Sea). Geophys. Res. Lett., 43, 6427-6434.

Josey, S.A., Somot, S., Tsimplis, M., 2011. Impacts of atmospheric modes of variability on Mediterranean Sea surface heat exchange. J. Geophys. Res. 116, C02032. doi:10.1029/2010JC006685

Kao, H.-Y., Lagerloef, G., Lee, T., Melnichenko, O., Meissner, T., Hacker, P., 2018. Assessment of Aquarius Sea Surface Salinity. Remote Sens. 10, 1341. doi:10.3390/rs10091341

Kolodziejczyk, N., Reverdin, G., Lazar, A., 2015. Interannual Variability of the Mixed Layer Winter Convection and Spice Injection in the Eastern Subtropical North Atlantic. J. Phys. Oceanogr. 45, 504-525. doi:10.1175/JPO-D-14-0042.1

Lee, T., 2016. Consistency of Aquarius sea surface salinity with Argo products on various spatial and temporal scales. Geophys. Res. Lett. 43, 3857-3864. doi:10.1002/2016GL068822

Malanotte-Rizzoli, P., Artale, V., Borzelli-Eusebi, G.L., Brenner, S., Crise, A., Gacic, M., Kress, N., Marullo, S., Ribera d\&amp;apos;Alcalà, M., Sofianos, S., Tanhua, T., Theocharis, A., Alvarez, M., Ashkenazy, Y., Bergamasco, A., Cardin, V., Carniel, S., Civitarese, G., 
D\&amp;apos;Ortenzio, F., Font, J., Garcia-Ladona, E., Garcia-Lafuente, J.M., Gogou, A., Gregoire, M., Hainbucher, D., Kontoyannis, H., Kovacevic, V., Kraskapoulou, E., Kroskos, G., Incarbona, A., Mazzocchi, M.G., Orlic, M., Ozsoy, E., Pascual, A., Poulain, P.-M., Roether, W., Rubino, A., Schroeder, K., Siokou-Frangou, J., Souvermezoglou, E., Sprovieri, M., Tintoré, J., Triantafyllou, G., 2014. Physical forcing and physical/biochemical variability of the Mediterranean Sea: a review of unresolved issues and directions for future research. Ocean Sci. 10, 281-322. doi:10.5194/os-10-281-2014

Mariotti, A., 2010. Recent Changes in the Mediterranean Water Cycle: A Pathway toward LongTerm Regional Hydroclimatic Change? J. Clim. 23, 1513-1525. doi:10.1175/2009JCLI3251.1

Martínez-Asensio, A., Marcos, M., Tsimplis, M.N., Gomis, D., Josey, S., Jordà, G., 2014. Impact of the atmospheric climate modes on Mediterranean sea level variability. Glob. Planet. Change 118, 1-15. doi:10.1016/j.gloplacha.2014.03.007

Menna, M., Poulain, P.-M., Zodiatis, G., Gertman, I., 2012. On the surface circulation of the Levantine sub-basin derived from Lagrangian drifters and satellite altimetry data. Deep Sea Res. Part I Oceanogr. Res. Pap. 65, 46-58. doi:10.1016/j.dsr.2012.02.008

Meissner, T., Wentz, F.J., 2004. The complex dielectric constant of pure and sea water from microwave satellite observations. IEEE Trans. Geosci. Remote Sens. 42, 1836-1849. doi:10.1109/TGRS.2004.831888

Meissner, T., Wentz, F.J., Scott, J., Vazquez-Cuervo, J., 2016. Sensitivity of Ocean Surface Salinity Measurements From Spaceborne L-Band Radiometers to Ancillary Sea Surface Temperature. IEEE Trans. Geosci. Remote Sens. 54, 7105-7111. doi:10.1109/TGRS.2016.2596100

Meissner, T., Wentz, F.J., LeVine, D.M., 2018. The Salinity Retrieval Algorithms for the NASA Aquarius Version 5 and SMAP Version 3 Releases. Remote Sens. 10, 1121. doi: $10.3390 /$ rs 10071121

Millot, C., Taupier-Letage, I., 2005. Circulation in the Mediterranean Sea. Springer, Berlin, Heidelberg, pp. 29-66. doi:10.1007/b107143

Millot, C., Gerin, R., 2010. The Mid-Mediterranean Jet Artefact. Geophys. Res. Lett. 37. doi:10.1029/2010GL043359

Myers, P.G., Haines, K., 2000. Seasonal and Interannual Variability in a Model of the Mediterranean under Derived Flux Forcing. J. Phys. Oceanogr. 30, 1069-1082. doi:10.1175/1520-0485(2000)030<1069:SAIVIA>2.0.CO;2

Nittis, K., Tziavos, C., Bozzano, R., Cardin, V., Thanos, Y., Petihakis, G., Schiano, M.E., Zanon, F., 2007. The M3A multi-sensor buoy network of the Mediterranean Sea. Ocean Sci. 3, 229-243. doi:10.5194/os-3-229-2007 
Olmedo, E., Taupier-Letage, I., Turiel, A., Alvera-Azcárate, A., 2018. Improving SMOS Sea Surface Salinity in the Western Mediterranean Sea through Multivariate and Multifractal Analysis. Remote Sens. 10, 485. doi:10.3390/rs10030485

Ozer, T., Gertman, I., Kress, N., Silverman, J., Herut, B., 2017. Interannual thermohaline (19792014) and nutrient (2002-2014) dynamics in the Levantine surface and intermediate water masses, SE Mediterranean Sea. Glob. Planet. Change 151, 60-67. doi:10.1016/j.gloplacha.2016.04.001

Özsoy, E., Hecht, A., Ünlüata, Ü., 1989. Circulation and hydrography of the Levantine Basin. Results of POEM coordinated experiments 1985-1986. Prog. Oceanogr. 22, 125-170. doi:10.1016/0079-6611(89)90004-9

Poulain, P.-M., Menna, M., Mauri, E., 2012. Surface Geostrophic Circulation of the Mediterranean Sea Derived from Drifter and Satellite Altimeter Data. J. Phys. Oceanogr. 42, 973-990. doi:10.1175/JPO-D-11-0159.1

Reul, N., Fournier, S., Boutin, J., Hernandez, O., Maes, C., Chapron, B., Alory, G., Quilfen, Y., Tenerelli, J., Morisset, S., Kerr, Y., Mecklenburg, S., Delwart, S., 2014. Sea Surface Salinity Observations from Space with the SMOS Satellite: A New Means to Monitor the Marine Branch of the Water Cycle. Surv. Geophys. 35, 681-722. doi:10.1007/s10712-0139244-0

Reynaud, Thierry, Kolodziejczyk, Nicolas, Maes, Christophe, Gaillard, Fabienne, Reverdin, Gilles, Desprez De Gesincourt, Floriane, Le Goff, Hervé (2015). Sea Surface Salinity from Sailing ships: Delayed mode dataset, annual release. SEANOE. https://doi.org/10.17882/39476

Rio, M.-H., Poulain, P.-M., Pascual, A., Mauri, E., Larnicol, G., Santoleri, R., 2007. A Mean Dynamic Topography of the Mediterranean Sea computed from altimetric data, in-situ measurements and a general circulation model. J. Mar. Syst. 65, 484-508. doi:10.1016/j.jmarsys.2005.02.006

Roemmich, D., Gilson, J., 2009. The 2004-2008 mean and annual cycle of temperature, salinity, and steric height in the global ocean from the Argo Program. Prog. Oceanogr. 82, 81-100. doi:10.1016/j.pocean.2009.03.004

Schroeder, K., Garcìa-Lafuente, J., Josey, S.A., Artale, V., Nardelli, B.B., Carrillo, A., Gačić, M., Gasparini, G. Pietro, Herrmann, M., Lionello, P., Ludwig, W., Millot, C., Özsoy, E., Pisacane, G., Sánchez-Garrido, J.C., Sannino, G., Santoleri, R., Somot, S., Struglia, M., Stanev, E., Taupier-Letage, I., Tsimplis, M.N., Vargas-Yáñez, M., Zervakis, V., Zodiatis, G., 2012. Circulation of the Mediterranean Sea and its Variability, in: The Climate of the Mediterranean Region. Elsevier, pp. 187-256. doi:10.1016/B978-0-12-416042-2.00003-3 
Skliris, N., Zika, J.D., Herold, L., Josey, S.A., Marsh, R., 2018. Mediterranean sea water budget long-term trend inferred from salinity observations. Clim. Dyn. 51, 2857-2876. doi:10.1007/s00382-017-4053-7

Tsimplis, M.N., 2005. Mediterranean Sea level trends: Atmospheric pressure and wind contribution. Geophys. Res. Lett. 32, L20602. doi:10.1029/2005GL023867 


\section{Figures}

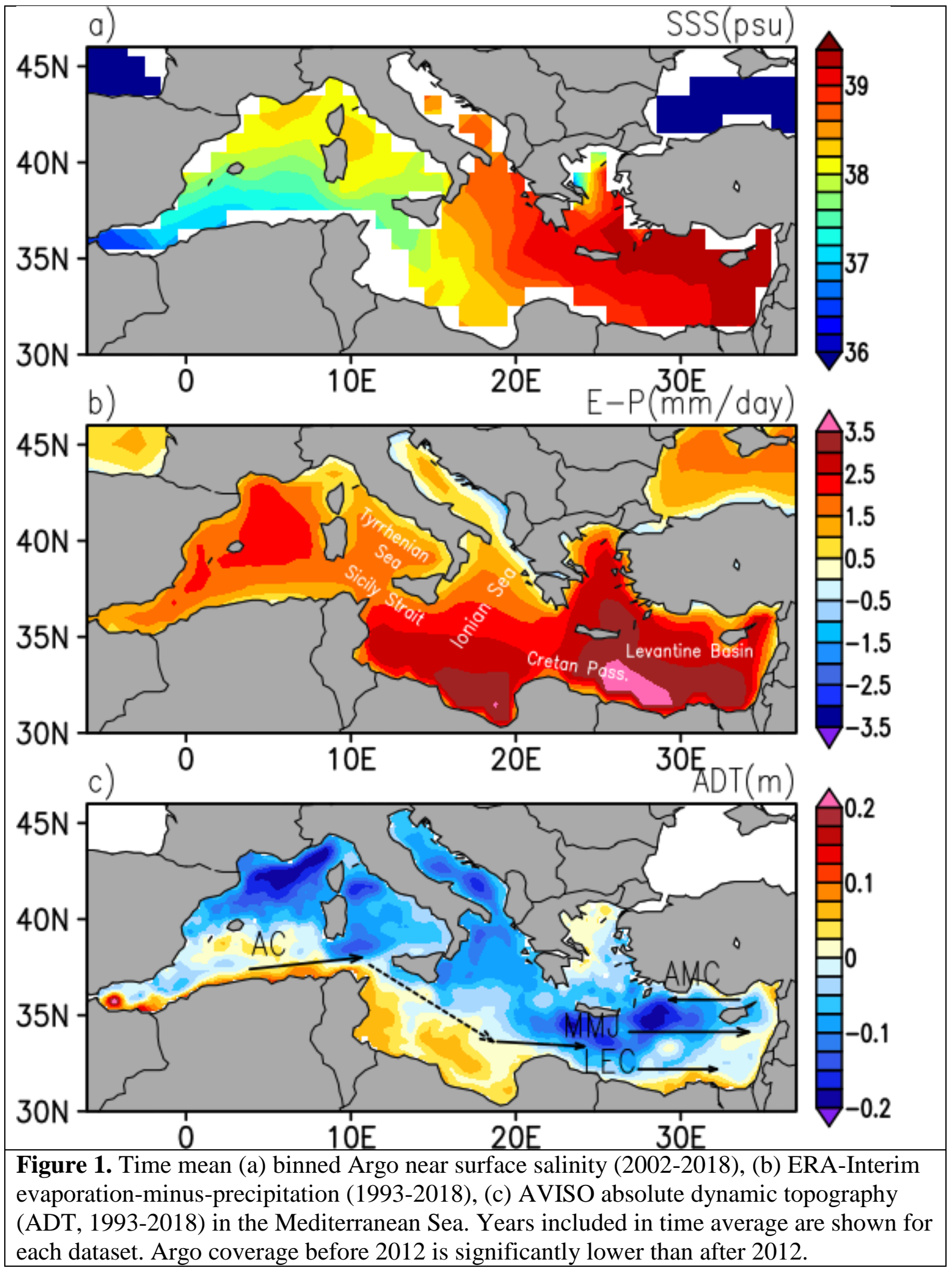




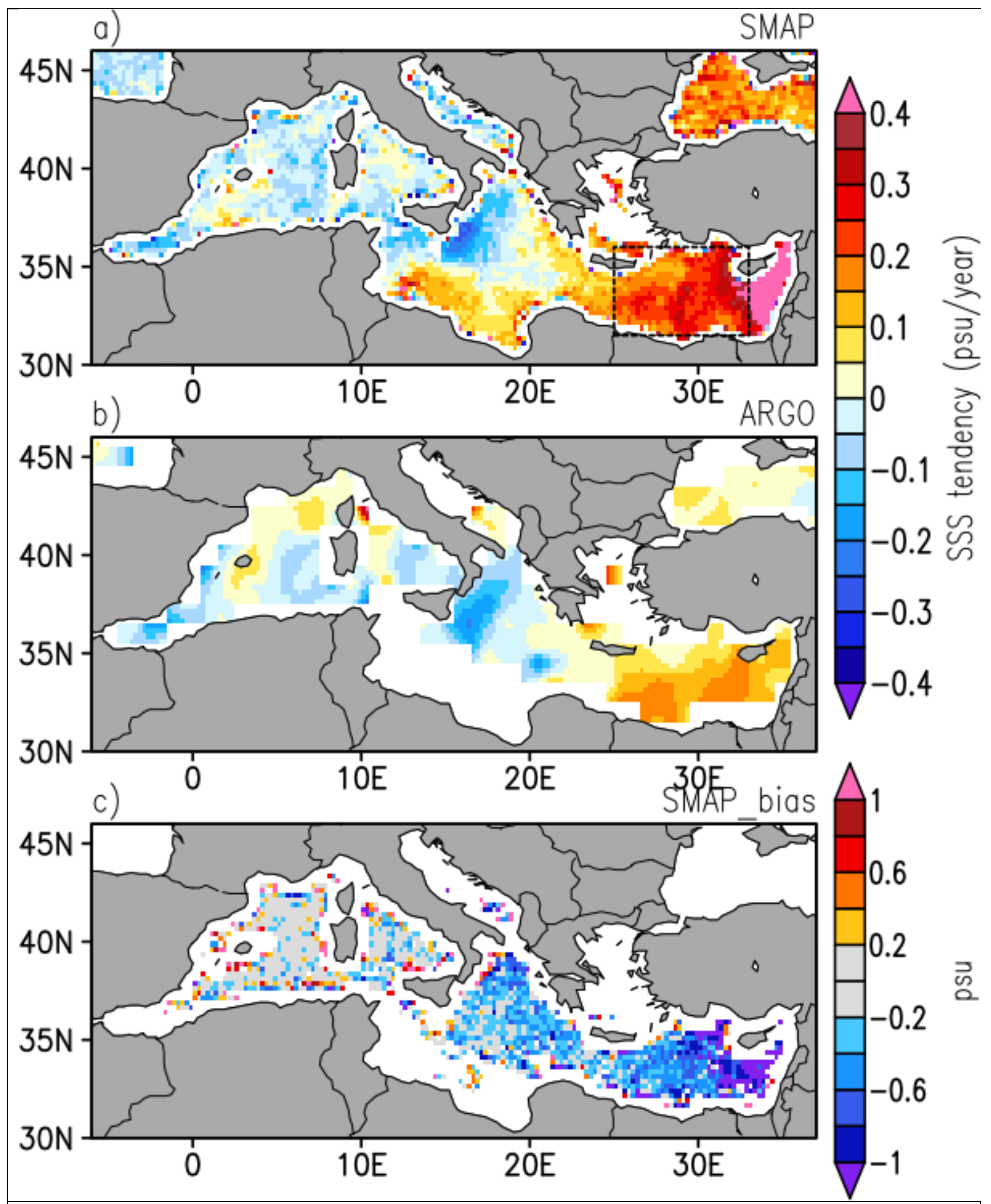

Figure 2. Linear temporal tendency of monthly SSS from (a) SMAP, (b) binned Argo during SMAP observation period 04/2015-onward. Argo SSS tendency is blanked if less than 6 months of data are available. The rectangle in (a) encompasses the Levantine basin index area. (c) SMAP SSS bias versus collocated $( \pm 12 \mathrm{~h}, \pm 20 \mathrm{~km})$ near-surface salinity from Argo and TSG. 


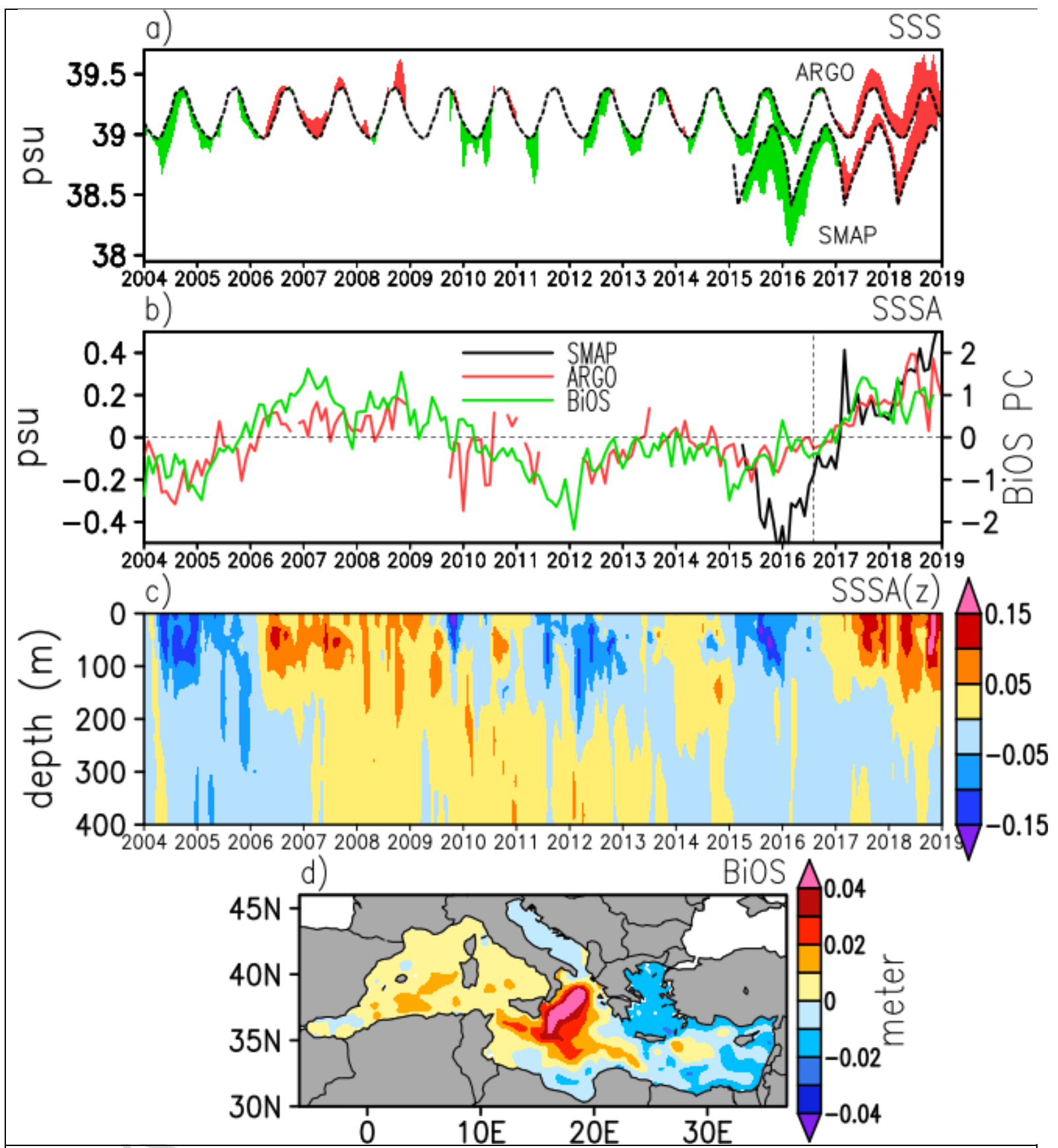

Figure 3. Salinity time series averaged over the Levantine index area shown in Fig. 2a: (a) SMAP and Argo SSS, dashed lines show the seasonal cycle, negative/positive anomalies are shaded green/red, respectively, (b) SMAP and Argo SSS anomalies (SSSA), (c) SSS anomalies from Argo/SCRIPT analysis versus depth, (d) the Adriatic- Ionian Bimodal Oscillation System, BiOS, mode of anomalous monthly sea level (Gacic et al., 2011). BiOS time series is included in (b) against the right hand y-axis. BiOS EOF is estimated over the entire satellite altimetry period since 1993. Data are shown for Argo analysis period since 2004. Vertical line in (b) corresponds to August 2016. 


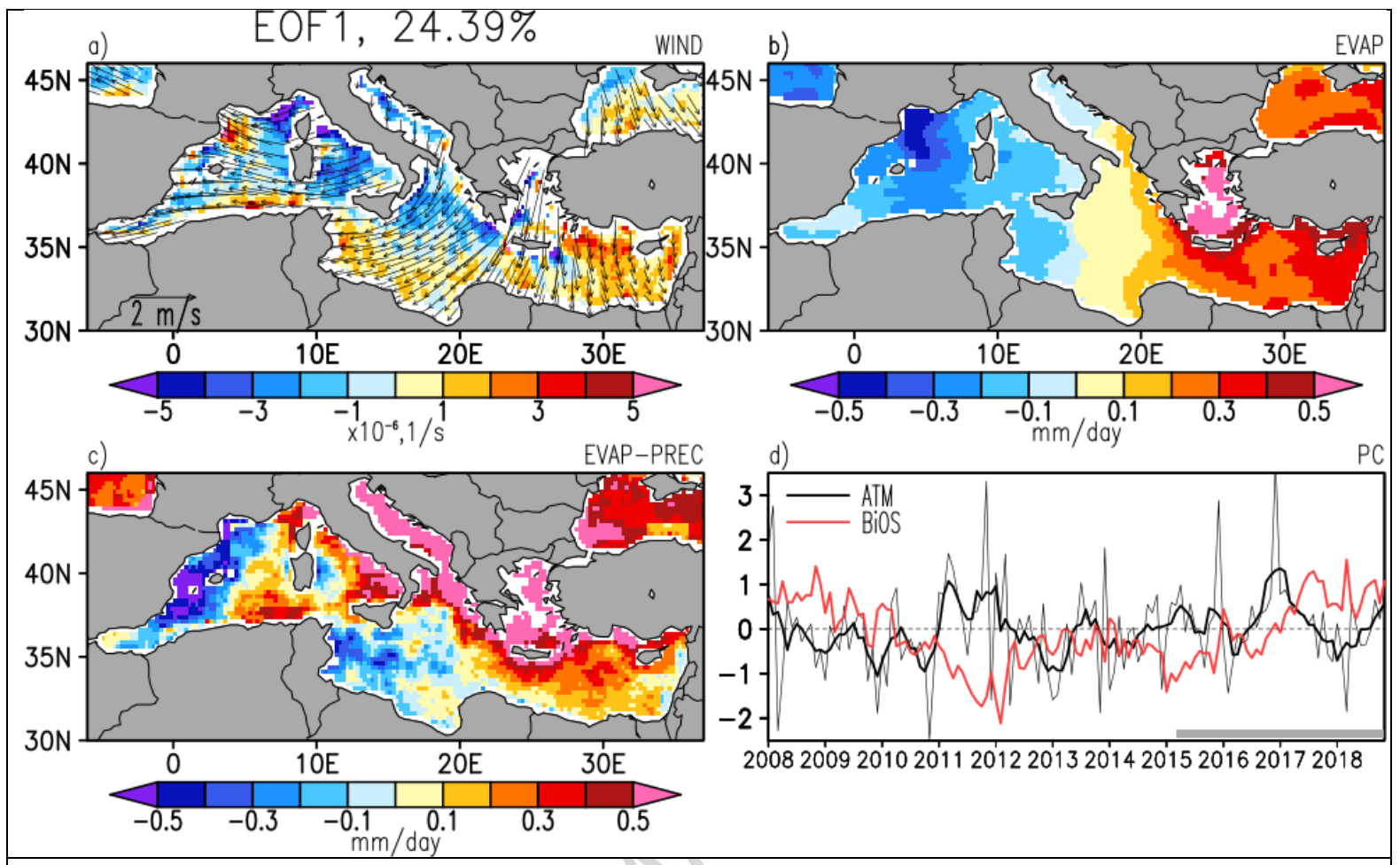

Figure 4. Leading multivariate EOF of anomalous (a) wind, (b) evaporation, (c) evaporation-minus-precipitation, (d) corresponding temporal principal component (PC) monthly (thin) and 5-month smoothed (bold). Shading in (a) is wind curl estimated from wind velocity EOF (arrows in panel a). SMAP period is shaded in (d). BiOS amplitude from Fig. $3 b$ is also included in (d). Percentage of explained variance is shown in (a). 


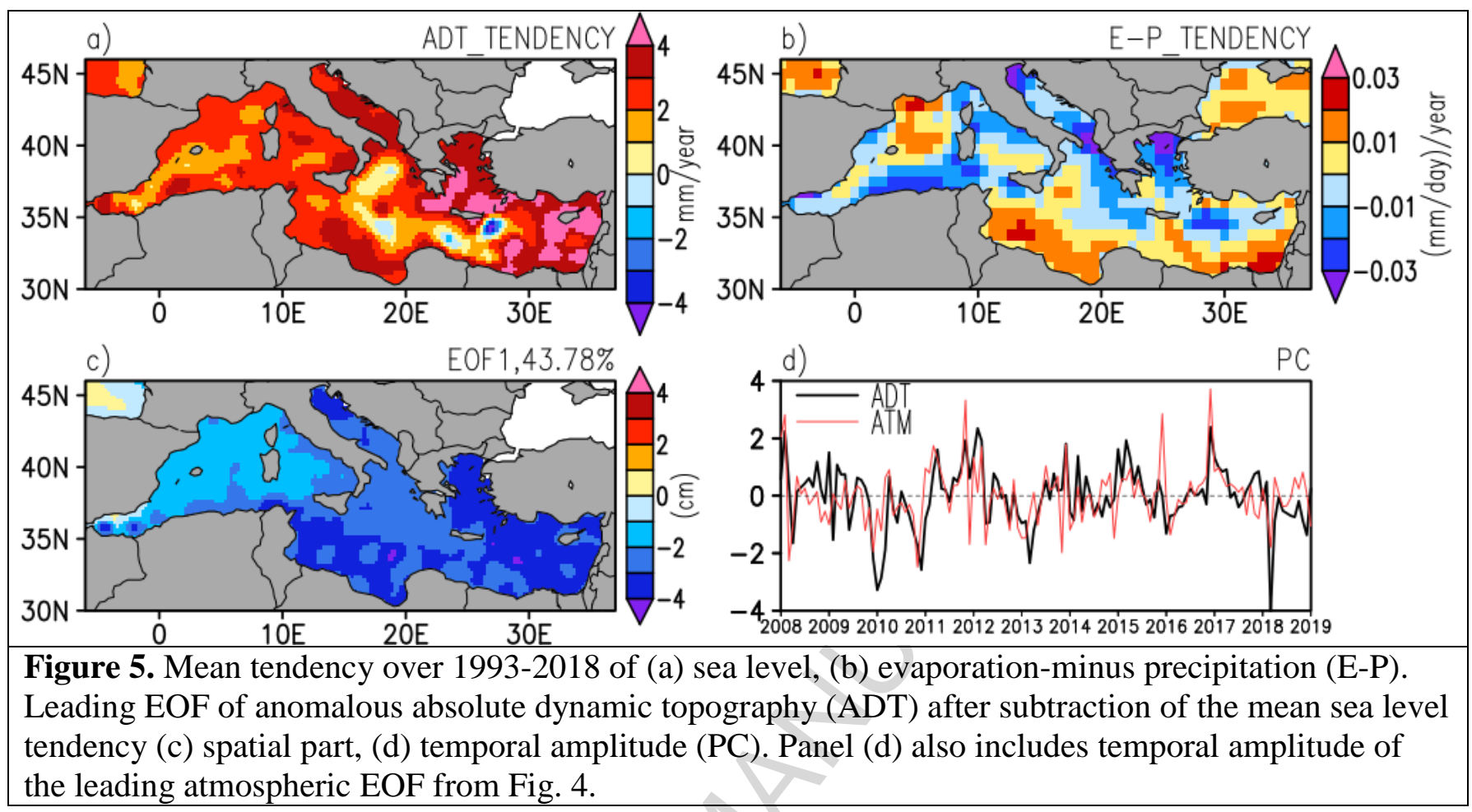




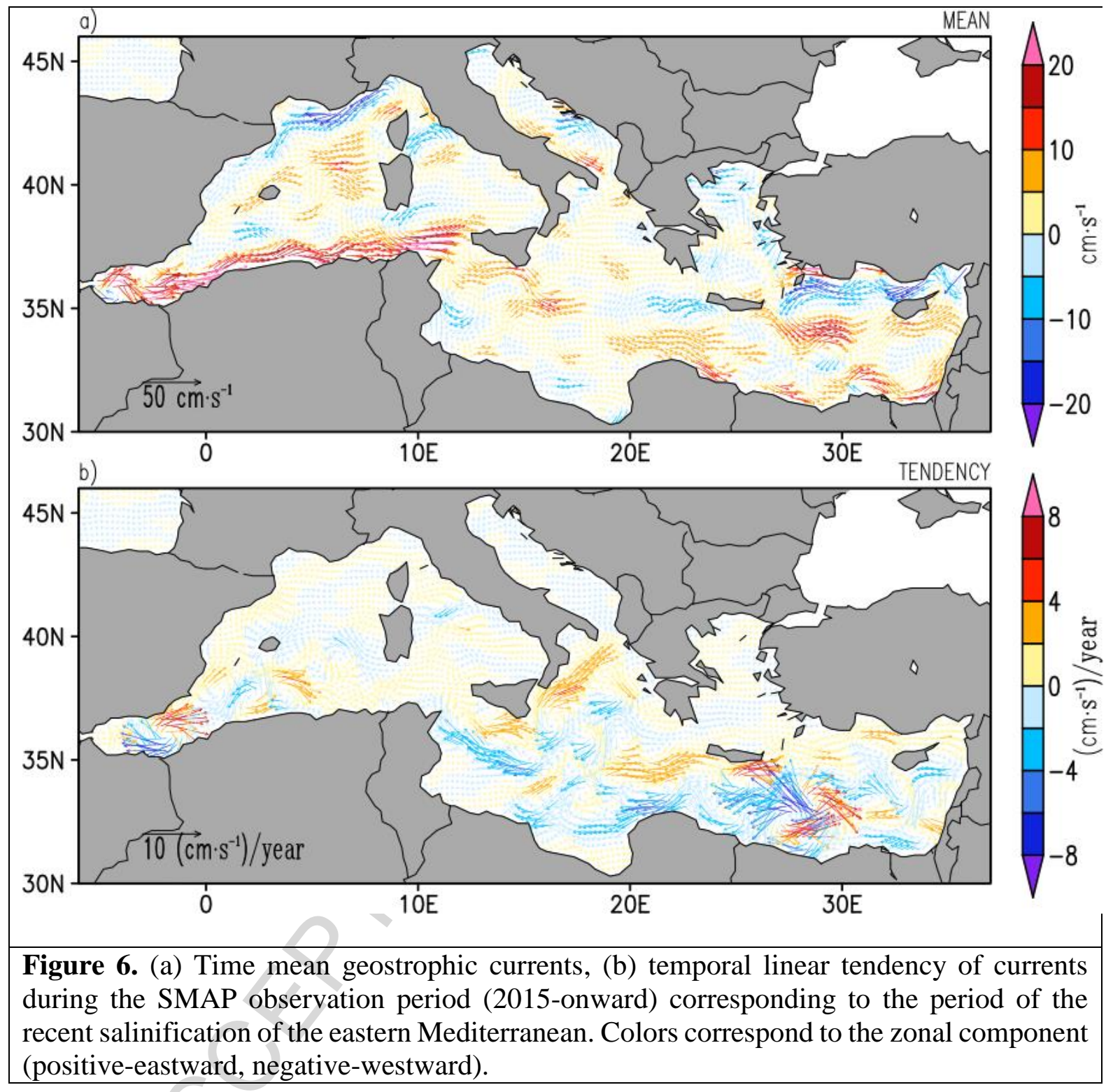




\section{Appendix Figures.}

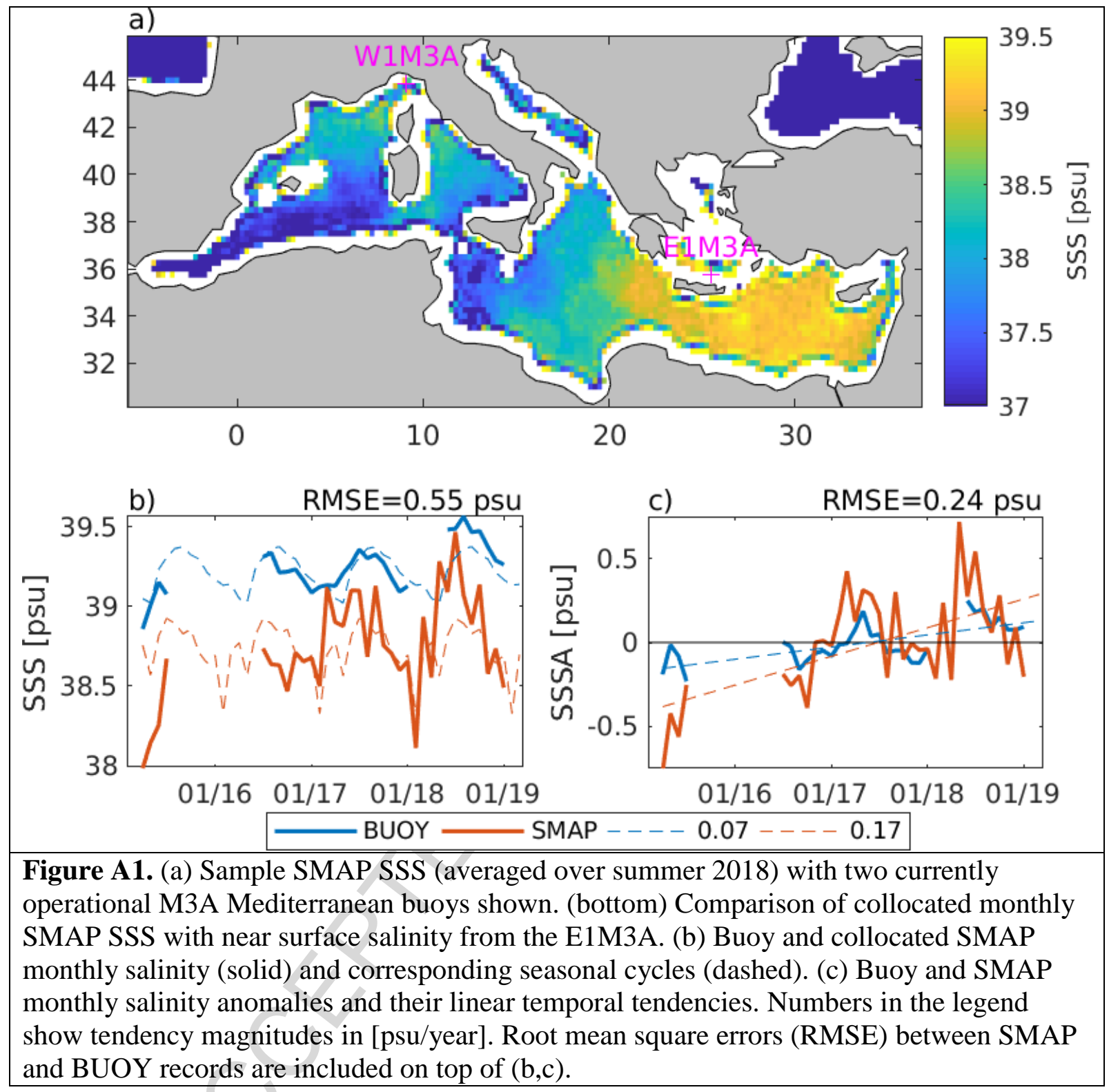




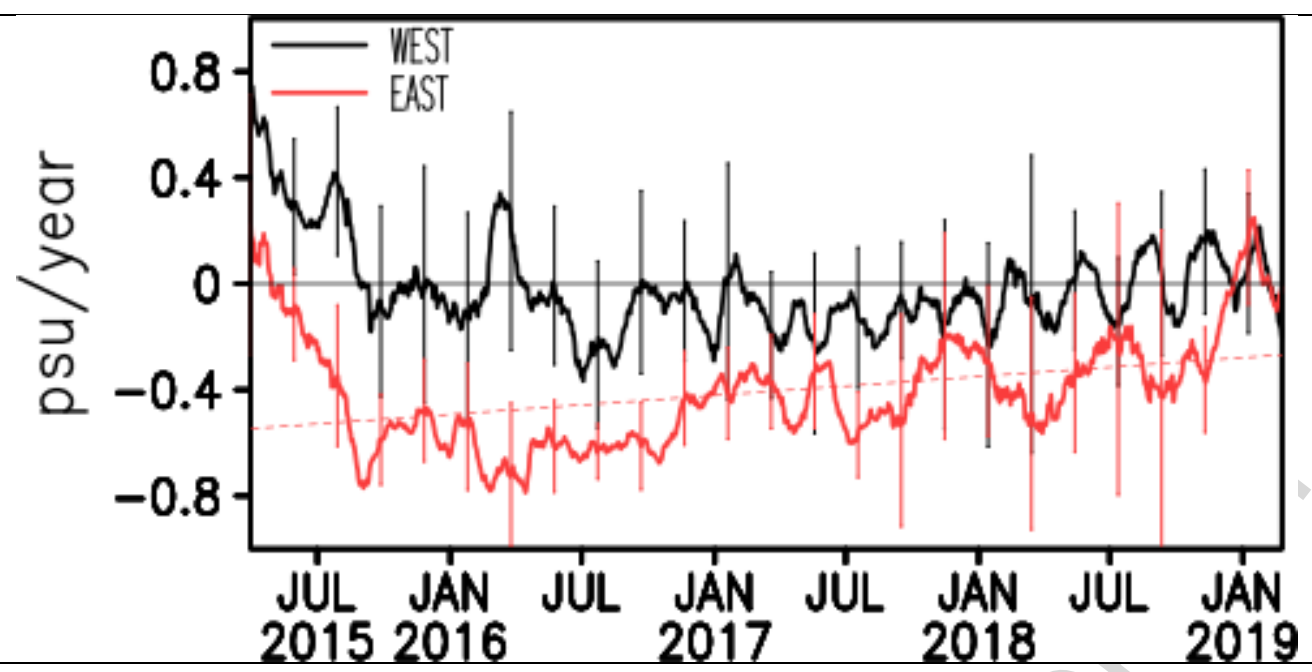

Figure A2. Temporal variation of SMAP bias versus $( \pm 12 \mathrm{~h}, \pm 20 \mathrm{~km})$ nearsurface salinity from Argo and TSG spatially averaged over western $\left(\mathrm{LON}<15^{\circ} \mathrm{E}\right)$ and eastern $\left(\mathrm{LON}>15^{\circ} \mathrm{E}\right)$ sectors of the Mediterranean Sea. Temporal tendency of SMAP SSS bias in the eastern sector $(0.08 \pm$ $0.02 \mathrm{psu} /$ year) is shown by red dash line. Vertical bars show STD of SMAP/in-situ match-ups within 1-month interval. Bias time series are daily data smoothed by running monthly mean. 


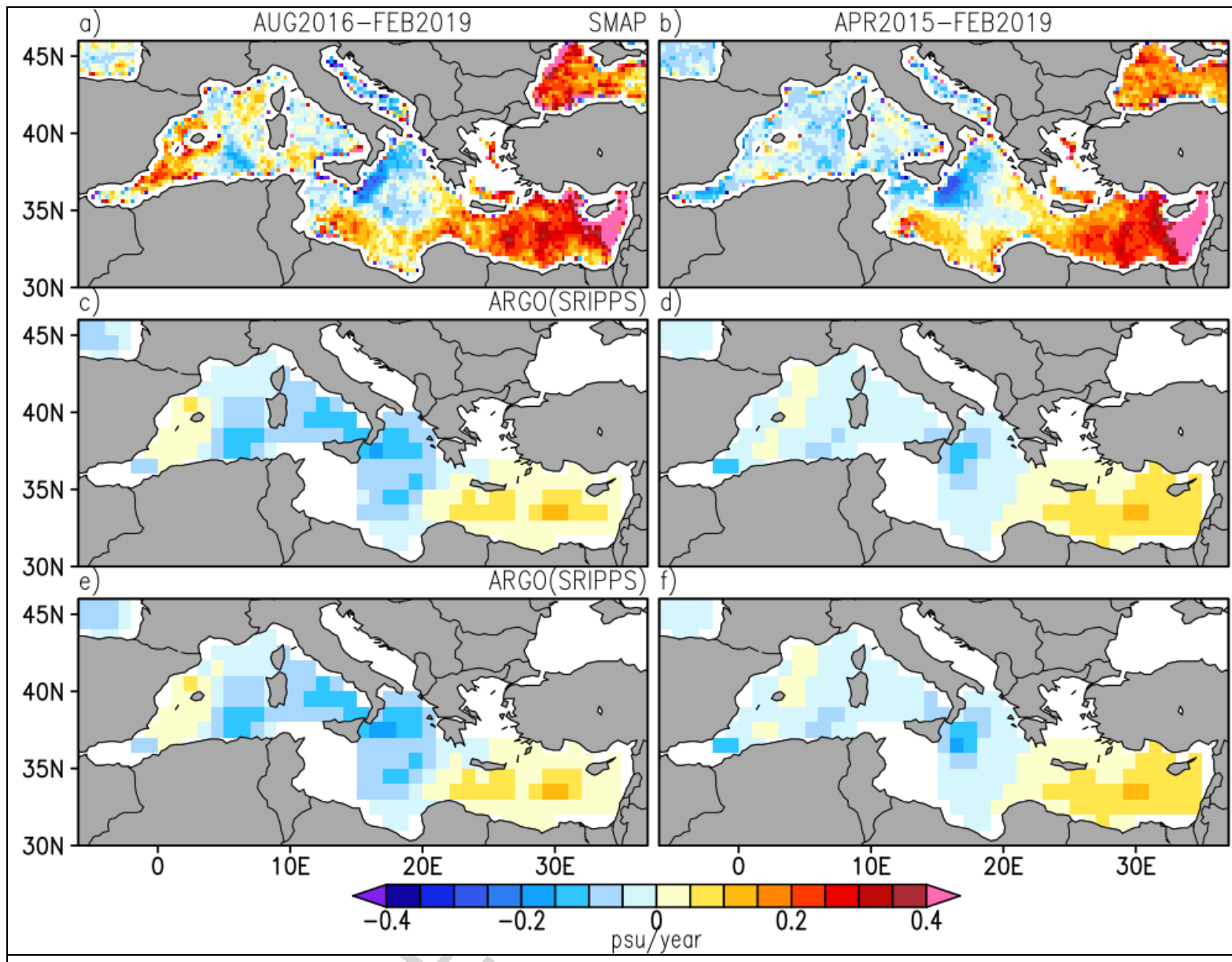

Figure A3. Sea surface salinity tendency estimated over (left) August 2016 - February 2019 and (right) the entire SMAP period (April 2015 - February 2019). Left column estimates exclude the time period of strong fresh SMAP bias (see Fig. 3b). SSS tendency from (a,b) SMAP, (c-f) SCRIPPS Argo analysis. Two bottom rows compare Argo-based estimates with SSS anomalies calculated versus (c,d) whole Argo SSS climatology (since 2004) and (e,f) Argo SSS climatology based on SMAP observation period (April 2015- February 2019). 


\section{Highlights}

- Monitoring complexity of Mediterranean processes is an appealing target for remote sensing.

- Despite strong biases, Mediterranean geophysical signals are contained in satellite SSS fields.

- During 2015-2018, satellite SSS shows steady salinification of the Levantine at $\sim 0.14$ $\mathrm{psu} /$ year.

- Levantine salinification results from Ionic Sea circulation switch linked with the BIOS pattern.

- Satellite SSS compliments existing in-situ observation systems due to better spatial resolution. 